\title{
DE LA NORMATIVA A LA REALIDAD DE LOS PRIVADOS DE LIBERTAD EN BOLIVIA; UN ANÁLISIS SOBRE LA GARANTÍA DE LOS DERECHOS FUNDAMENTALES A LA SALUD E INFRAESTRUCTURA PENITENCIARIA*
}

\author{
From the regulations to the reality of the deprived of liberty \\ in Bolivia: an analysis on the guarantee of Fundamental Rights \\ such as health and penitential infrastructure
}

\section{Dos regulamentos à realidade dos privados de liberdade na Bolívia; análise da garantia de direitos fundamentais à saúde e à infraestrutura penitencial

\author{
Liliana Cano Burgoa ${ }^{a}$ \\ Icanob@univalle.edu \\ Alex Cabello Ayzamab
} ayzamalex@ufu.br}

Fecha de recepción: 2 de octubre de 2019 Fecha de revisión: 27 de noviembre de 2019 Fecha de aceptación: 01 de diciembre de 2019

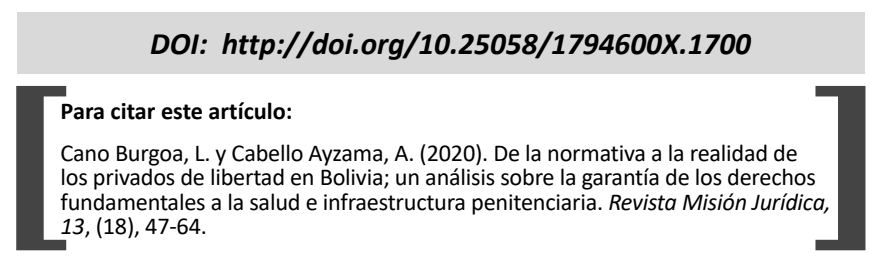

\section{RESUMEN}

En el presente artículo se realiza un análisis sobre la garantía de los derechos fundamentales a la salud e infraestructura por parte del Estado Plurinacional de Bolivia con relación a la población penitenciaria, además de un estudio sobre aquellos factores que inciden en el incremento de dicha población. A través del método deductivo se recopilaron y analizaron datos elaborados y presentados por instituciones de gobierno, en los que se identificaron una serie de aparentes vulneraciones de derechos fundamentales que transgreden la dignidad humana; especialmente aquellas que tienen que ver con el derecho a la salud y el derecho a una infraestructura adecuada en los recintos penitenciarios.

\footnotetext{
* Este artículo de reflexión surge como parte del Convenio de cooperación entre la Universidad del Valle (Bolivia) y la Universidad Federal de Uberlândia (Brasil). El interés del tema es compartido por los autores en razón de las últimas cifras sobre la población penitenciaria en Bolivia y las reformas jurídicas por parte del órgano legislativo que va dirigido al incremento de criminalización de las conductas humanas como una respuesta fácil al problema de educación y seguridad ciudadana lo cual se conoce como populismo penal. Los informes consultados, hacen ver que existe un relevante descuido a la población penitenciaria por parte del Estado central, al tiempo que no garantiza las condiciones mínimas de tratamiento hacia los reclusos y más aún que no garantiza el respeto por los derechos fundamentales de esta población, lo cual los convierte en un grupo desaventajado.

a. Legum Magister en Estudios Legales Internacionales en American University (Becaria Fulbright). Postgrado en UC Davis/ Berkeley. Diplomado en: Negociación, Conciliación y Arbitraje; Derecho Informático; Educación Virtual; Docencia Universitaria, y Ciencias Penales. Fue investigadora interna de la OEA en Washington DC y en la Agencia Española de Cooperación Internacional para el Desarrollo (AECID). También fue Asesora Legal en Potomac Legal Aid Inc. (Virginia), Actualmente Directora del Dpto. Académico de la Facultad de Ciencias Jurídicas y Políticas en la Universidad del Valle (Bolivia), docente de Métodos Alternativos y Solución de Controversias, Gestión Constructiva del Conflicto, Análisis e interpretación Jurídica y otros en pre-grado y postgrado.
} 


\section{PALABRAS CLAVE}

Derecho penitenciario; cárcel; derechos humanos; grupos vulnerables.

\begin{abstract}
This article analyzes the guarantee of the fundamental rights to health and infrastructure by the Plurinational State of Bolivia towards the prison population, in addition to a study on the factors that affect the increase of this population. Through the deductive method, data prepared and submitted by government institutions is collected and analyzed, in which a series of apparent violations of fundamental rights that transgress human dignity have been identified, especially those that are related to the right to health and the right to adequate infrastructure in prisons.
\end{abstract}

\section{KEYWORDS}

Penitentiary Law; jail; human rights; vulnerable groups.

\section{RESUMO}

Este artigo analisa a garantia dos direitos fundamentais à saúde e à infraestrutura do Estado Plurinacional da Bolívia em relação à população carcerária, além de um estudo sobre os fatores que afetam o aumento dessa população. Por meio do método dedutivo, são coletados e analisados os dados elaborados e apresentados pelas instituições governamentais, nos quais foram identificadas uma série de aparentes violações de direitos fundamentais que transgredem a dignidade humana, principalmente aquelas relacionadas ao direito à saúde, e o direito a infraestrutura adequada nas prisões.

\section{PALAVRAS CHAVE}

Lei Penitenciária; prisão; direitos humanos; grupos vulneráveis.

b. Graduado en Derecho por la Universidad Mayor de San Simón (Bolivia) Maestrante en Derecho por la Universidad Federal de Uberlândia (Brasil) Investigador en disciplinas de derechos humanos, derecho penal, migración, derecho internacional. Miembro de grupos de investigación: Red Jurídica Internacional RED compara Laboratorio Americano de Estudios Constitucionales Comparados LAECC - UFU. Este trabajo se realizó con el apoyo de la Coordinación de Mejora del Personal de Educación Superior - Brasil (CAPES) - Código de Financiamiento 001.

\section{INTRODUCCIÓN}

El derecho penitenciario es una de las materias poco estudiadas en Bolivia. A pesar de ser parte de la estructura relacionada con el derecho penal, su estudio ha quedado rezagado. Esta falta de interés puede considerarse como uno de los factores que responsables de la falta de análisis y propuestas sobre los recintos penitenciarios, así como de las políticas que permitan la garantía y el respeto a los derechos humanos en estos espacios. Sin embargo, las pocas instituciones que se dedican a realizar estudios al respecto, han tratado de mantenerse visibles a través de la publicación de estudios, evaluaciones y recomendaciones sobre los recintos penitenciarios que han reflejado un evidente descuido por parte del Estado.

La ausencia de políticas públicas y un plan estratégico de adecuado funcionamiento de los centros penitenciarios, ha dado lugar a que la autoridad del Estado, al interior de estos centros penitenciarios, sea rebasada por parte de los propios privados de libertad, lo cual deriva en que el papel de estos centros se reduzcan a ser ambientes de aislamiento vigilados por policías para que los infractores no puedan salir de ahí.

A pesar de que la última reforma constitucional en Bolivia (2009) ha otorgado fuerza normativa a los derechos fundamentales y ha endilgado la responsabilidad al Estado sobre la rehabilitación de los privados de libertad; se ha quedado pendiente la tarea sobre la elaboración de políticas públicas que permitan ejercer esa fuerza normativa de garantía de los derechos fundamentales en los centros penitenciarios, en donde la débil presencia del Estado ha dado lugar al pésimo comportamiento de los internos, lo cual ha terminado en tragedias seguidas de muerte ${ }^{1}$.

A eso se suman los serios problemas sobre administración de justicia; un estudio nombrado Informe sobre el estado de la justicia en Bolivia 2018, elaborado por la Plataforma Ciudadana por el Acceso a la Justicia y los Derechos Humanos (Plataforma, 2019), revela problemas estructurales relacionados con la estabilidad, independencia e imparcialidad de las y los operadores de justicia, que también llega a afectar

1. Una de las tragedias más relevantes en los últimos diez años fue la sucedida en el Centro Penitenciario Palmasola en 2018, con un saldo de siete personas fallecidas y más de veinte heridos. (Véase; Comunicado de Prensa de CIDH). 
a la administración de los centros penitenciarios y el abuso del poder punitivo a través del excesivo uso de las medidas cautelares de carácter personal, manteniendo a Bolivia entre uno de los países con mayor deficiencia en derecho penitenciario.

En tal sentido, el objetivo del presente trabajo se basa en realizar un análisis sobre la situación y la garantía de los derechos fundamentales de la población penitenciaria por parte del Estado, además de analizar las posibles causas sobre el incremento de la población penitenciaria que terminan en un alto índice de hacinamiento.

\section{CONCEPTUALIZACIÓN SOBRE DERECHO PENITENCIARIO}

El acatamiento de una sentencia condenatoria involucra cumplir con la última parte del proceso penal cuyo objetivo es la ejecución de la sentencia, el cual estará sujeto a regulación por parte del derecho penitenciario a razón del cumplimiento y respeto de las garantías y los derechos fundamentales de las personas privadas de libertad. Sergio García (1975) define el derecho penitenciario como el "conjunto de normas jurídicas que regulan la ejecución de las penas privativas de libertad" (p. 33), y al igual que el sistema penal, el derecho penitenciario ha pasado por reformas de acuerdo a la evolución de la sociedad. El surgimiento de la cárcel como una institución de castigo hacia las personas que han quebrantado las buenas costumbres y las leyes tiene una data muy antigua ${ }^{2}$ y fue avanzando de acuerdo a la configuración del derecho mismo, sin embargo, no ha cambiado su esencia de ser materialmente una institución de castigo.

La cárcel forma parte del derecho penal cuya existencia y vigencia depende del trabajo en conjunto de cada una de las instituciones del Estado, tal como lo indica Hulsman Louk (1993) citado por Enríquez (2013), "las prisiones hacen parte de una forma específica de cooperación entre la policía, las Cortes, Leyes los departamentos de criminología en el mundo académico, el Ministerio

2. Herlinda Enríquez Rubio (2012) realiza una narración cronológica sobre el proceso de evolución de la pena privativa de libertad, en tales antecedentes, se encuentra la obra del Prof. Emiro Sandoval Huertas, que ubica cuatro fases de la transformación de la pena ubicado en cada momento histórico: Vindicativa, expiacionista o retribucionista, correccionalista y resocializante. (Véase: Herlinda Enríquez Rubio, 2012, p. 10 y ss). de Justicia y el Parlamento. Conforman así, todas ellas, el derecho penal" (p. 20). De esta manera, la cárcel afianza su característica de ser una institución que concentra a las personas que han quebrantado la norma a través de la separación del resto de la sociedad, esto último también fue parte de un proceso de evolución, concluyendo en una política casi humanitaria con la tesis de resocialización.

De manera general, el Profesor Eugenio Zaffaroni identifica cuatro momentos discursivos sobre el carácter de pena de prisión (el moralizante, el peligrosista, el funcionalista y el anómico) explicados de la siguiente forma:

Un primer momento de raíz especulativa, donde el delito y la locura eran el producto de una existencia desordenada $\mathrm{y}$, por ende, se hacía necesario someter a la persona a un régimen de vigilancia y encierro en un panóptico. El segundo momento al cual Zaffaroni lo indica como positivismo peligrosista, para el cual el penado era una persona peligrosa a la que había que someter a un tratamiento reductor de la peligrosidad. El tercer momento discursivo, generalizado a partir de la Segunda Guerra Mundial, en que se adoptaron conceptos de teorías sociológicas. De la mano de Talcott Parsons se introdujo orgánicamente la idea del tratamiento como «resocialización ${ }^{3} »[. .$. A partir de los años sesenta comienza el proceso de decadencia de la criminología etiológica y van arreciando las críticas a la prisión desde el punto de vista sociológico progresista y desde el ángulo político criminal reaccionario: unos ponen de relieve el efecto deteriorante de la prisión; otros responsabilizan al «tratamiento» por el alto número de reincidencias. Atrapado por la tenaza que forman las críticas provenientes del progresismo y de la reacción, el discurso de la criminología clínica se fue derrumbando, la criminología etiológica se desprestigió y, de esta manera, el tratamiento sufre, en cuanto a su ideología o filosofía, un cuarto momento, que bien

3. De acuerdo al autor, para Parsons existe una socialización que, si fracasa, da lugar a conductas desviadas que el sistema debe corregir mediante su control. Esta idea proviene esencialmente desde el pensamiento estructural funcionalismo de Parsons, indica que la estructura social funciona como un mecanismo operativo parecido a los sistemas biológicos o incluso informáticos, es una formación autónoma y funcional en donde sus partes deben operar satisfactoriamente para no alterar el orden o status quo de su entorno; en ese orden de ideas los seres humanos atraviesan una serie de procesos en los que adquieren y desarrollan funciones (Véase: Leonardo Villamil, 2017, p. 28). 
puede ser calificado como «momento anómico ${ }^{4}$ » (Zaffaroni, 1997, pp. 180-181).

Los últimos dos movimientos descritos por Zaffaroni, pasan a configurar las características del actual sistema penitenciario en América Latina, el Jurista realiza una crítica sobre el tercer movimiento y la irrupción de conceptos más difusos como "«readaptación social», «reinserción social», «reeducación», «repersonalización» e incluso un uso impreciso de la propia «resocialización», todos caracterizados por el prefijo «re», que construía la idea de algo que había fallado y que justificaba una segunda intervención" (Zaffaroni, 2015, p. 16). Esta idea de tratamiento para un mejoramiento, se encuentra como idea rectora de gran parte de las legislaciones de derecho penitenciario y también en instrumentos jurídicos de carácter internacional cuyo objetivo en común es la reinserción social del interno a través de diversos mecanismos y políticas que deben ser garantizadas por los Estados.

Leonardo Villamil (2017) desenvuelve la idea del estructural funcionalismo de Talcott Parsons (1951) desde las categorías de desviación social e institución. De esta manera, la desviación social se explica como una tendencia motivada "a comportarse en contravención de una o más pautas normativas institucionalizadas" (Parsons, 1951, p.163). Esta contravención podrá ser individual (actor individual) o colectiva (sistema interactivo) momento en el que dichos comportamientos serán contrarrestados por los mecanismos de control social. Cuando el o los actores se encuentran en esta posición de contravención de las pautas normativas institucionalizadas, es que se considera como una desviación social, dando lugar al posicionamiento de la cárcel como institución reformadora, cuyo objetivo es reintegrar a los disidentes de la norma.

\section{MARCO NORMATIVO INTERNACIONAL SOBRE DERECHO PENITENCIARIO}

4. Término introducido por Emile Durkheim, para referirse a aquellos casos en el que la crisis es tan profunda que el sistema normativo tiende a caerse. También puede explicarse como la ausencia de un cuerpo de normas que gobiernen las relaciones entre las diversas funciones sociales que ante su ausencia $y / 0$ debilitamiento, los individuos dejan de tener clara la diferencia entre lo justo y lo injusto, lo legítimo y lo ilegítimo (Véase: María del Pilar López, 2009, p. 135 y ss.). El mismo Durkheim ha explicado que la prisión ha sobrevivido porque satisface el deseo popular de infligir castigo a los infractores y apartarlos de la vida social normal sin importar cuáles sean los costos o las consecuencias de largo plazo.
La preocupación por el desarrollo del derecho penitenciario sobre la base de mínimas condicionas y enmarcadas en el respeto a los derechos humanos proviene desde 1926, año que se iniciaron las mesas de trabajo que buscaban uniformar el derecho penitenciario. Este anhelo no se llega a plasmar hasta 1955, año en el que se aprobaron las Reglas Mínimas para el Tratamiento de los Reclusos, en el marco del I Congreso de las Naciones Unidas sobre Prevención del Delito y Tratamiento del Delincuente y posteriormente aprobada por el Consejo Económico y Social. De alguna manera, la culminación de la Segunda Guerra Mundial y la aprobación de la Declaración Universal de los Derechos Humanos en 1948, sirvieron como punto directriz para trabajar las políticas penitenciarias en marco del respeto de los derechos humanos de la población penitenciaria.

Las Reglas Mínimas para el Tratamiento de los Reclusos; reconocen que la prisión y demás medidas cuyo efecto es separar a un delincuente del mundo exterior son aflictivas por el hecho mismo de que despojan al individuo de su derecho a disponer de su persona al privarle de su libertad. En el mismo sentido, este documento reconoce que no tiene como objeto especificar las condiciones de un sistema penitenciario modelo, solo el de establecer principios y reglas de una buena organización penitenciaria y de la práctica relativa al tratamiento de los reclusos en razón que entiende la variedad de condiciones jurídicas, sociales, económicas y geográficas existentes en el mundo que imposibilitan la aplicación indistinta de todas las reglas en el mismo tiempo.

Con una base contemplada en el respeto a los derechos humanos, las Reglas Mínimas para el Tratamiento de los Reclusos establecen las pautas de aplicación general cuyo principio fundamental se basa en la aplicación imparcial sin justificación de tratos fundados en prejuicios de raza, color, sexo, lengua, religión, etc. Instituye directrices para un tratamiento adecuado con base en el registro de los privados de libertad, la separación de categorías (de acuerdo a edad, sexo, detenidos de forma preventiva y condenada y el tipo de delito), infraestructura, servicios básicos, alimentación, servicios médicos, educación, religión y clasificación, apelando a que los Estados puedan garantizar en lo posible el respeto de los derechos humanos. 
Por otra parte, recomienda que antes del cumplimiento de la condena impuesta se puedan adoptar los medios necesarios para asegurar al recluso un retorno progresivo a la vida en sociedad. Esta recomendación se conocería como sistema progresivo; que trata de ser no solo una garantía de tratamiento, también de rehabilitación y reinserción gradual a la sociedad, "en el sentido de viabilizar pari passu un restablecimiento del contacto y lazos con la sociedad otrora mantenidos por el recluso" (Barbosa Da Silva, 2018, p. 13).

La constante evolución del derecho penitenciario y la legislación internacional obligó a que las Reglas Mínimas para el Tratamiento de los Reclusos pasen por una revisión iniciada en $2011^{5}$ a petición de la Asamblea General a través de la conformación de un grupo intergubernamental, tarea que finalizó en 2015. En el marco de la cuarta reunión de la Comisión de Prevención del Delito y Justicia Penal se aprobaron las reglas revisadas, siendo posteriormente remitidas al Consejo Económico Social para su aprobación y consiguientemente a la Asamblea General para que se adoptaran. La Asamblea General además de adoptar la revisión de las Reglas Mínimas para el Tratamiento de los Reclusos adoptó la inclusión del nombre de "Reglas Nelson Mandela"6.

A pesar que estas reglas no son de carácter vinculante en razón de la variedad de marcos jurídicos de los Estados que ya se habían expresado en el primer documento, alienta a que los Estados Miembros se esfuercen por mejorar las condiciones de reclusión, procurando limitar el hacinamiento en las cárceles a través del fortalecimiento de las medidas sustitutivas del encarcelamiento y apoyando los programas de rehabilitación y reinserción social, en tal razón; el Pacto Internacional de Derechos Civiles y Políticos indica que el Régimen Penitenciario consistirá en un tratamiento cuya finalidad esencial será la

5. De acuerdo a la resolución $65 / 230$, de 21 de diciembre de 2010 en marco del $12^{\circ}$ Congreso de las Naciones Unidas sobre Prevención del Delito y Justicia Penal", en la que solicitó a la Comisión de Prevención del Delito y Justicia Penal. Posteriormente de acuerdo a las resoluciones 67/188 de 20 de diciembre de 2012, 68/190, de 18 de diciembre de 2013 y 69/192, de 18 de diciembre de 2014, en las que se tomó nota sobre el inicio y avance del trabajo de revisión de las Reglas Mínimas.

6. La inclusión del nombre "Nelson Mandela", es un homenaje al legado del difunto Presidente de Sudáfrica, Nelson Rolihlahla Mandela, quien pasó 27 años en prisión durante su lucha por los derechos humanos, la igualdad, la democracia y la promoción de una cultura de paz a nivel mundial. reforma y la readaptación social de los penados, por lo que es jurídicamente vinculante para sus Estados partes ${ }^{7}$.

Estructuralmente la revisión se concentró en nueve puntos consistentes en: El respeto a la dignidad y el valor inherente de los reclusos como seres humanos, los servicios médicos y sanitarios, las medidas y sanciones disciplinarias, la investigación de las muertes de reclusos, la protección y las necesidades especiales de los grupos vulnerables privados de libertad, el derecho a representación letrada, las quejas y las inspecciones independientes, la sustitución de terminología obsoleta y la capacitación del personal pertinente a fin que aplique las Reglas Mínimas.

Entre las reglas que resaltan por su carácter de importancia por el respeto de los derechos humanos, se pueden mencionar:

Tabla 1. Comparación entre los derechos contemplados en la Declaración Universal de Derechos Humanos y las Reglas Mandela

\begin{tabular}{|c|c|c|}
\hline DERECHO & REGLA & $\begin{array}{c}\text { DECLARACIÓN } \\
\text { DD.HH }\end{array}$ \\
\hline $\begin{array}{l}\text { Derecho a la } \\
\text { igualdad y } \\
\text { dignidad humana. }\end{array}$ & $\begin{array}{l}\text { Reglas } 1,2,5(2), 34, \\
42,45,50,52 .\end{array}$ & Arts. 1,10 \\
\hline $\begin{array}{l}\text { Derecho a la vida } \\
\text { y a no sufrir tratos } \\
\text { inhumanos }\end{array}$ & $\begin{array}{l}\text { Reglas } 34,43,45 \text {, } \\
47,48,82 .\end{array}$ & $\begin{array}{l}\text { Arts. } 3,5,12 \text {, } \\
25 .\end{array}$ \\
\hline $\begin{array}{l}\text { Separación por } \\
\text { categorías (Edad, } \\
\text { sexo, antecedentes } \\
\text { penales, situación } \\
\text { jurídica) }\end{array}$ & $\begin{array}{l}\text { Reglas 11, 12(2), } \\
81 .\end{array}$ & \\
\hline $\begin{array}{l}\text { Derecho a los } \\
\text { servicios básicos }\end{array}$ & $\begin{array}{l}\text { Reglas } 14,15,16 \text {, } \\
17,18(1), 42 .\end{array}$ & Art. 25. \\
\hline $\begin{array}{l}\text { Derecho a la } \\
\text { alimentación }\end{array}$ & Regla 22. & Art. 25. \\
\hline $\begin{array}{l}\text { Derecho al } \\
\text { esparcimiento }\end{array}$ & Regla 23. & \\
\hline Derecho a la salud & $\begin{array}{l}\text { Reglas } 24,25,26, \\
27,28,30,31,32, \\
34,35,46(2) \text { y (3). }\end{array}$ & Art. 25. \\
\hline
\end{tabular}

Fuente: Elaboración propia

7. Conforme indica el artículo 10, párrafo 3, del Pacto Internacional de Derechos Civiles y Políticos, resolución 2200A (XXI) de la Asamblea General, (Véase: Evaluación del cumplimiento de las Reglas Nelson Mandela, 2017, p. 17 y ss). 
De la misma forma, las Reglas Mínimas detallan la importancia de la diferencia de garantías entre las personas privadas de libertad que ya han recibido una condena y las que aún se encuentran siendo sujetos de investigación, con una medida cautelar en su contra en resguardo del principio de inocencia. Ese detalle es el que mantiene la discusión en la actualidad por cuanto no existe una garantía real de la separación por categorías y el abuso de las medidas cautelares, provocando un hacinamiento desmedido en los centros penitenciarios.

Además de las Reglas Mínimas para el Tratamiento de los Reclusos se cuentan con otras normas de carácter internacional como los Principios y Buenas Prácticas sobre la Protección de las Personas Privadas de Libertad en las Américas, Conjunto de Principios para la Protección de todas las Personas Sometidas a Cualquier forma de Detención o Prisión, Reglas mínimas de las Naciones Unidas sobre las Medidas no Privativas de la Libertad (Reglas de Tokio) ${ }^{8}$, Reglas de las Naciones Unidas para el Tratamiento de las Reclusas y Medidas no Privativas de la Libertad para las Mujeres Delincuentes (Reglas de Bangkok ${ }^{9}$ y Reglas Mínimas de las Naciones Unidas para la Administración de la Justicia de Menores (Reglas de Beijing) ${ }^{10}$.

\section{MARCO JURÍDICO Y REFORMA JUDICIAL EN EL ESTADO PLURINACIONAL DE BOLIVIA}

La última reforma constitucional en Bolivia modificó materialmente el bloque de constitucionalidad, albergando dentro de sus niveles a los Tratados e Instrumentos internacionales en materia de derechos humanos por encima de las leyes infraconstitucionales $y$, en casos concretos, con aplicación preferente

8. Aprobada por la Asamblea General de acuerdo a la Resolución 45/110 de 14 de diciembre de 1990. Contiene principios que promueven la aplicación de medidas no privativas de libertad.

9. Aprobada por la Asamblea General de acuerdo a la Resolución A/RES/65/229 de 21 de diciembre de 2010. Tiene como objetivo el de instar a los Estados Miembros, a que las políticas penitenciarias relacionadas con las mujeres deban basarse en ellas, contienen principios y reglas básicas para el tratamiento especial bajo perspectiva de género.

10. Adoptadas por la Asamblea General de acuerdo a la Resolución 40/33 de 29 de noviembre de 1985. Contiene normas pormenorizadas para la administración de justicia de menores, tiene por objeto el bienestar del menor, evitando, en lo posible, su paso por el sistema de justicia de menores. sobre la propia Constitución ${ }^{11}$. El bloque de constitucionalidad se refiere a aquellas normas que, sin ser parte del texto constitucional, son utilizadas como parámetros del control de constitucionalidad de las leyes, específicamente en normativa internacional sobre derechos humanos. Al respecto, la Sentencia Constitucional 0045/2006 de 2 de junio (Bolivia, 2006), explica que queda claro que no todo tratado, declaración, convención o instrumento internacional es parte del bloque de constitucionalidad, sino sólo aquellos referidos a los derechos humanos. En tal sentido y de acuerdo al art. 410 de la Constitución Política del Estado, este bloque de constitucionalidad se encuentra integrado por los Tratados y Convenios internacionales en materia de Derechos Humanos y las normas de Derecho Comunitario, ratificados por el país ${ }^{12}$.

Esa reforma constitucional dio lugar al inicio del proceso de saneamiento jurídico de las leyes infraconstitucionales, adecuándose a la norma rectora de la constitución y los tratados internacionales en materia de derechos humanos. Sin embargo, algunos cuerpos legales de gran importancia quedaron con esta tarea pendiente y pasaron simplemente por reformas superficiales de complementación, sin tocar el fondo. Entre esas normas se encuentran el

11. Al respecto, la Constitución Política del Estado Plurinacional de Bolivia, a través de su art. 256, establece la aplicación preferente de tratados e instrumentos internacionales en materia de derechos humanos sobre la constitución, sin embargo, en el art. 410 dice: La Constitución es la norma suprema del ordenamiento jurídico boliviano y goza de primacía frente a cualquier otra disposición normativa. El bloque de constitucionalidad está integrado por los Tratados y Convenios internacionales en materia de Derechos Humanos y las normas de Derecho Comunitario, ratificados por el país. Dentro ese marco, se desarrolla una discusión sobre la aplicación preferente de tratados e instrumentos internacionales en materia de derechos humanos sobre la constitución, dicho debate inicia con una Sentencia Constitucional emitido por el Tribunal Constitucional Plurinacional de Bolivia (0084/2017) mediante el que resuelve declarar la aplicación preferente del art. 23 de la Convención Americana sobre Derechos Humanos, por ser favorable en relación a derechos políticos en relación a los arts. 156, 168, 285.II y 288 de la Constitución Política del Estado.

12. Al respecto, es importante mencionar la Sentencia Constitucional 0045/2006 de 2 de junio, que junto a las Sentencias Constitucionales $N^{\circ} 1662 / 2003-R y$ 1420/2004- $R$, han sentado las bases para una conceptualización y reconocimiento del bloque de constitucionalidad en Bolivia, indicando que el bloque de constitucionalidad en Bolivia lo conforman, además del texto de la constitución, los tratados, las declaraciones y convenciones internacionales en materia de derechos humanos ratificados, dejando en claro que de dicha comprensión, solo es posible aceptar a las normas internacionales dentro del bloque de constitucionalidad, cuando existe una permisión expresa en la Constitución 
Código Penal ${ }^{13}$, Código de Procedimiento Penal, y la Ley de Ejecución Penal; estos tres cuerpos legales se encuentran relacionados entre sí; ya que desenvuelven y sistematizan todo el proceso en materia penal; desde el inicio de investigaciones, desarrollo del proceso de investigación, hasta concluir con la ejecución y la vigilancia del cumplimiento de la condena; de manera conjunta, refleja la política criminal sobre la cual Bolivia trabaja al momento de otorgar respuestas sobre comportamientos socialmente reprochables.

Anterior a la reforma constitucional, Bolivia dirigió su camino hacia la consolidación gradual de un sistema penal acusatorio a través de la Ley de Procedimiento Penal (Ley 1970) de 1999, que marcó el inicio de un trabajo preparativo sobre la política y ruta que el reformado sistema penal acusatorio debiera seguir para cumplir sus objetivos. De acuerdo a Arturo Yáñez (1999): "el sistema acusatorio oral se remonta a Grecia democrática y Roma republicana, en los que la dignidad y libertad del ser humano reciben tratamiento preferente del ordenamiento jurídico, posibilitando así en mayor medida el respeto de los derechos humanos". En tal sentido, es que la reforma mencionada, se presenta con una pluralidad de elementos asentados sobre la base de la garantía de los derechos fundamentales, garantizando la oportunidad de estar presentes ante un juez imparcial para ser oídos sin demora ni perjuicio, dejando atrás al sistema penal mixto14; una fórmula híbrida

13. En el caso de este cuerpo normativo (Código Penal) se promulgó una reforma total a través de la Ley 1005 de 15 de diciembre de 2017, cuyo espíritu se concentraba en un sistema de justicia con enfoque restaurativo y de prevención, sin embargo, no ingresó en vigencia, afrontando una primera derogatoria de artículos mediante Ley 1025 de 10 de enero de 2018 y finalmente, su abrogación a través de la Ley 1027 de 25 de enero de 2018. La razón de su abrogatoria fue la falta de consenso entre los sectores involucrados, toda vez que el nuevo cuerpo legal planteaba reformas con endurecimiento de penas, creaba nuevos delitos y en algunos casos llegaban a colisionar con la Constitución Política del Estado. Esa falta de consenso, desembocó en un gran conflicto social, que obligó al gobierno a dar marcha atrás, abrogando la nueva Ley penal.

14. Siguiendo la línea de explicación propuesta por Manuel Aráuz (2002) dentro del sistema penal mixto, la persecución penal y averiguación de la verdad comprendida como meta absoluta del principio inquisitivo se mezclan con los valores o atributos de la personalidad humana. En los términos señalados debe analizarse si en realidad el proceso mixto participa de la naturaleza acusatoria o solamente comporta la forma inquisitiva. A este respecto la doctrina (Binder, Maier, Zaffaroni) ha respondido que no puede señalarse como proceso mixto aquel proceso cuyo único indicio acusatorio es el impulso procesal y la resolución de la causa por un tribunal de jurados, pues ello entre el sistema penal acusatorio y el inquisitivo. Este último, representa lo contrario del sistema penal acusatorio, es propio de sistemas políticos autoritarios, en donde el acusado es objeto y no sujeto de investigación, no existiendo un límite de autoridad en el respeto o garantía de los derechos fundamentales.

Uno de los principales retos que contemplaba el nuevo sistema penal acusatorio consistía en consolidar de manera objetiva la división de funciones, tanto del Ministerio Público como del Juez Instructor. Esto se traduce en la función del Ministerio Público como único encargado de la actividad persecutoria cuya investigación se desarrollará con la ayuda de la policía judicial y el Instituto de Investigaciones Forenses ${ }^{15}$, ambas instituciones desarrollan sus actividades investigativas bajo la dirección del Ministerio Público. Por otra parte, el Juez Instructor es el encargado de controlar que dicho proceso de investigación se desarrolle en marco a los límites establecidos tanto dentro de la Constitución Política del Estado como de las leyes infraconstitucionales, amparando el respeto de los derechos fundamentales y las garantías procesales ${ }^{16}$.

no hace desaparecer su naturaleza inquisitiva. Para que un proceso penal pueda considerarse como mixto debe en principio acordarse la etapa de la investigación a un órgano jurisdiccional especializado, distinto del juez de la causa, igualmente en la fase plenaria debe primar sobre todo la oralidad y la publicidad; debe de garantizar además la inmediación del Juez o Tribunal desde el inicio del plenario donde necesariamente deben reproducirse las pruebas de la fase de instrucción so pena de tenerlas por inexistentes (Véase: Aráuz, 2002,37).

15. De esta manera, la Constitución Política del Estado Plurinacional de Bolivia, a través de su art. 225 explica que el Ministerio Público es el encargado de la defensa de la legalidad y los intereses generales de la sociedad. En lo que respecto la defensa de la sociedad, C. Alejandro Lara (2010) explica la existencia de dos instituciones, "la primera denominada Defensoría del Pueblo y la segunda Ministerio Público". Ya en el tema procedimental; el código de procedimiento penal boliviano, establece en su art. 70, las tareas específicas del Ministerio Público de investigar y promover la acción penal pública ante los órganos jurisdiccionales. La colaboración de investigación entre el Ministerio Público, la Policía y el Instituto de Investigaciones Forenses, se encuentra contemplado en el art. 69 del mismo cuerpo legal.

16. La labor del Juez Instructor se encuentra regulado a través de la Ley 025, cuyo art. 74 explica que entre las labores de las juezas y jueces de instrucción penal se encuentran: El control de la investigación, conforme a facultades y deberes previstos por ley, emitir las resoluciones jurisdiccionales que correspondan durante la etapa preparatoria y de la aplicación de criterios de oportunidad, además de sustanciar el proceso abreviado, aprobar el acta de conciliación en los asuntos de su conocimiento si la ley así lo permite, entre otras. Procedimentalmente, el art. 54 del Código de Procedimiento Penal, indica las competencias de los jueces de instrucción. 
Si bien la tarea del Ministerio Público se extiende hasta llegar a un escenario de juicio oral público y contradictorio en el que tendrá que sostener y defender la acusación ante un Tribunal de Sentencia, el trabajo del Juez Instructor termina juntamente a la etapa preparatoria recibiendo la última resolución como resultado de la investigación del Ministerio Público mediante la que puede presentar una acusación 0 , en todo caso, sobreseer al imputado. Es entonces que "la figura del juez de instrucción garantiza la presencia jurisdiccional" (Bastarreche, 2013, p.107) siendo más un juez de garantías porque no ejerce una función investigadora al igual que el Ministerio Público no realiza actos jurisdiccionales.

Otro de los desafíos que perseguía la reforma del sistema penal era el uso limitado del poder punitivo, que a decir de Luigi Ferrajoli (2006) la noción de un derecho penal mínimo corresponde a la idea del garantismo en materia penal, que intenta poner fuertes y rígidos límites a la actuación del poder punitivo del Estado. Ferrajoli explica que se tratan de "garantías penales sustanciales: del principio de estricta legalidad o taxatividad de los comportamientos punibles a los de lesividad, materialidad y culpabilidad" (Ferrajoli, 2006, p.38). Para Raúl Zaffaroni (2002), esta acción planificada de reducción del poder punitivo, "impulsa el progreso del estado de derecho [...] siendo el componente dialéctico indispensable para su subsistencia y progreso". En tal sentido, esos esfuerzos de reforma y reconducción estaban dirigidos a evitar la persecución penal en hechos de escasa relevancia social y principalmente la racionalización de la aplicación de medidas cautelares de carácter personal. En lo relativo al proceso, se establecieron las garantías procesales como la presunción de inocencia, el principio de contradicción, el acceso a una justicia oportuna, la creación de plazos fatales para la resolución de casos, a no ser obligado a declarar contra sí mismo ni a confesarse culpable y del derecho al juez legal o natural.

\subsection{DERECHO PENITENCIARIO EN BOLIVIA}

En lo concerniente al derecho penitenciario, la Constitución plantea un sistema de respeto y garantía de los derechos humanos en todos los ámbitos: civil, político, económico social, cultural, justicia, paz y solidaridad. Esta reforma se interesó por establecer las políticas que el Estado debe asumir y visibilizar los derechos sobre las personas privadas de libertad. De esta forma, el Estado asume la responsabilidad sobre la implementación de políticas públicas que permitan la reinserción social de las personas privadas de libertad ${ }^{17}$. Estas políticas públicas por lo general están concentradas en la rehabilitación del condenado a través de programas de estudio y trabajo bajo un régimen de disciplina.

Bolivia utiliza e interpreta los conceptos de la teoría o ideología «re» para fundamentar su sistema penitenciario cuyas tareas de reinserción, control y vigilancia sobre la ejecución de las penas privativas de libertad se encuentran reguladas a través de una ley específica conocida como la Ley de Ejecución Penal (Ley 2298), que, en síntesis, representa al derecho penitenciario. La aplicación de los conceptos de la teoría o ideología «re», ha cedido el espacio para que los recintos penitenciarios sean percibidos más como un castigo que como una forma de rehabilitación, en gran medida por el descuido del Estado al momento de aplicar las políticas sobre atención a la población privada de libertad.

En ese orden de ideas; el art. 3 de esta ley señala que la pena tiene por finalidad proteger a la sociedad contra el delito, lograr la enmienda, readaptación y reinserción social del condenado a través de una cabal comprensión y respeto de la ley. De esta forma la cárcel se presenta como una institución de castigo, vigilancia y aislamiento que, al mismo tiempo, trata de cumplir un rol de reeducación, separando al sujeto de la sociedad por considerarlo como un peligro para la sociedad $^{18}$. A pesar del proceso de saneamiento jurídico que afrontó Bolivia desde la última reforma constitucional, la Ley 2298 no ha sufrido

17. Al respecto, el art. 74 de la Constitución Política del Estado, indica que: Es responsabilidad del Estado la reinserción social de las personas privadas de libertad, velar por el respeto de sus derechos, y su retención y custodia en un ambiente adecuado, de acuerdo a la clasificación, naturaleza y gravedad del delito, así como la edad y el sexo de las personas retenidas. Las personas privadas de libertad tendrán la oportunidad de trabajar y estudiar en los centros penitenciarios. El trabajo y estudio hacen parte de las políticas públicas implementadas por el Estado cuyo objetivo es la de concientizar, reeducar y rehabilitar al interno.

18. A esta acción, Goffman (1972) lo clasifica como parte del tercer tipo de institución total "organizado para proteger a la comunidad contra quienes constituyen intencionalmente un peligro para ella, no se propone como finalidad inmediata el bienestar de los reclusos" (p. 18). 
ninguna modificación, tomando en cuenta sus dieciocho años de vigencia cuyo espíritu se basa en la readaptación y reinserción social del sujeto condenado a pena privativa de libertad a través de un sistema progresivo, consistente en el avance gradual de los distintos periodos de tratamiento basados en tres ejes fundamentales: disciplina, trabajo y estudio.

Los dos últimos ejes de trabajo y estudio son garantizados en alguna medida por el Estado en colaboración con diversas organizaciones nacionales e internacionales. Así por ejemplo, en el caso del trabajo, los privados de libertad desarrollan diferentes actividades al interior de los recintos penitenciarios, principalmente trabajos manuales como carpintería y trabajos con metal, que son comercializados por sus familias o en ferias anuales que son organizadas por el Estado. Por otro lado, para garantizar que los privados de libertad puedan acceder a una formación técnica o profesional, se firman convenios interinstitucionales, principalmente con universidades públicas que colaboran con la guía y formación de los privados de libertad. Estas actividades permiten garantizar la consolidación del sistema progresivo para que los privados de libertad aprendan algunas habilidades técnicas para cuando recuperen su libertad.

Estas tareas y objetivos señalados por la Constitución Política del Estado y la Ley 2298 se encuentran bajo el control y supervisión de un Juez especial, denominado Juez de Ejecución Penal; encargado del control jurisdiccional, y la permanente vigilancia del respeto a los derechos y garantías determinadas en la Constitución Política del Estado y Tratados Internacionales que establecen reglas específicas en cuanto al tratamiento de la población penitenciaria.

De acuerdo al Informe Defensorial 2018 elaborado por la oficina de la Defensoría del Pueblo del Estado Plurinacional de Bolivia (2018), el país cuenta con 20 centros penitenciarios distribuidos en áreas urbanas, la mayoría de estos centros se encuentran distribuidos por el eje troncal del país ${ }^{19}$ tal como se detalla en la siguiente tabla:

Tabla 2. Población penitenciaria al año 2017

\begin{tabular}{|c|c|c|c|}
\hline $\mathbf{N}^{\circ}$ & RECINTO PENITENCIARIO ${ }^{20}$ & DEPARTAMENTO & POBLACIÓN \\
\hline 1 & Centro Penitenciario Femenino de Miraflores & LA PAZ & 71 Pers. \\
\hline 2 & Centro de Orientación Femenina de Obrajes & LA PAZ & 298 Pers. \\
\hline 3 & Centro de Rehabilitación de Qalauma & LA PAZ & 236 Pers. \\
\hline 4 & Centro Penitenciario de San Pedro & LA PAZ & 2412 Pers. \\
\hline 5 & Centro Penitenciario de San Pedro de Chonchocoro & LA PAZ & 370 Pers. \\
\hline 6 & Centro Penitenciario San Pedro & ORURO & 719 Pers. \\
\hline 7 & $\begin{array}{l}\text { Centro de Readaptación Productiva Santo Domingo } \\
\text { de Cantumarca }\end{array}$ & POTOSÍ & 484 Pers. \\
\hline 8 & El Abra & COCHABAMBA & 763 Pers. \\
\hline 9 & San Sebastián Varones & СОСНАВАМВА & 764 Pers. \\
\hline
\end{tabular}

19. Se denomina eje troncal, a las ciudades con más población distribuidas de la siguiente manera: La Paz (2.883.494 hab.), Cochabamba (1.971.523 hab.) y Santa Cruz (3.224.662 hab.) de acuerdo a los datos del Instituto Nacional de Estadística (INE).

20. Solo se toman en cuenta los principales recintos penitenciarios del país detallados en la investigación citada, sin embargo, se conoce sobre la existencia de otros recintos penitenciarios de menor población ubicados en regiones medianas o pequeñas que suman en total 32 "carceletas" a nivel nacional. 


\begin{tabular}{|c|c|c|c|}
\hline $\mathbf{N}^{\circ}$ & RECINTO PENITENCIARIO ${ }^{20}$ & DEPARTAMENTO & POBLACIÓN \\
\hline 10 & San Sebastián Mujeres & COCHABAMBA & 228 Pers. \\
\hline 11 & San Antonio & COCHABAMBA & 493 Pers \\
\hline 12 & San Pablo de Quillacollo & COCHABAMBA & 382 Pers. \\
\hline 13 & San Pedro de Sacaba & COCHABAMBA & 249 Pers. \\
\hline 14 & Centro Penitenciario San Roque & CHUQUISACA & 595 Pers. \\
\hline 15 & Centro Penitenciario Morros Blancos & TARIJA & 564 Pers. \\
\hline 16 & Centro de Rehabilitación Palmasola Varones & SANTA CRUZ & 5154 Pers. \\
\hline 17 & Centro de Rehabilitación Palmasola Mujeres & SANTA CRUZ & 374 Pers. \\
\hline 18 & Mocoví Varones & BENI & 496 Pers. \\
\hline 19 & Centro de Rehabilitación de Trinidad Mujeres & BENI & 34 Pers. \\
\hline 20 & Villa Busch & PANDO & 437 Pers. \\
\hline
\end{tabular}

Fuente: Elaboración propia a partir de estudio de Defensoría del Pueblo (2018).

De acuerdo a la información presentada en el anterior cuadro, se puede evidenciar que las ciudades con mayor índice de población como La Paz, Cochabamba y Santa Cruz ${ }^{21}$ albergan más centros penitenciarios y por ende mayor población penitenciaria. Sin embargo, cada uno de estos centros penitenciarios mantiene un sistema de organización propia, a través de delegados internos y Consejo Penitenciario ${ }^{22}$. La Ley 2298 permite a los privados de libertad contar con una representación ante las autoridades administrativas y judiciales a través de la elección anual de delegados internos y delegados procuradores, estos últimos cumplen la tarea de averiguar el estado de los procesos y colaborar con diversos trámites que los privados de libertad

21. En el caso de Santa Cruz, a diferencia de las demás ciudades, cuenta con una sola institución llamada Centro de Rehabilitación Palmasola. Sin embargo, su gran extensión le permite albergar mayor cantidad de internos a diferencia de otros centros penitenciarios del país.

22. El Consejo Penitenciario está compuesto el Director del establecimiento, que lo preside, los responsables de las áreas de asistencia, el responsable de la junta de trabajo y el responsable de la junta de educación. Sus funciones comprenden en la clasificación de los condenados en el sistema progresivo y el asesoramiento al Director del establecimiento en asuntos de su competencia. puedan requerir ${ }^{23}$. En cambio, la labor de los delegados internos adquiere más relevancia en razón de ser parte de la Junta de Trabajo, Junta de Educación y el Consejo Penitenciario, este último es la instancia encargada de la clasificación de los privados por los niveles de acuerdo al sistema progresivo.

Se entiende como sistema progresivo a la política implementada por el Estado cuyo objetivo es rehabilitar al condenado a través de la distribución del tiempo de la condena en diversos periodos, a través de los cuales van adquiriendo ciertos beneficios penitenciarios que se encuentran condicionados a la demostración de buena conducta e interés por el trabajo o el estudio. Este sistema progresivo está compuesto por cuatro periodos, distribuidos y caracterizados de la siguiente manera:

Tabla 3. Sistema progresivo en el sistema penitenciario boliviano

23. De acuerdo al art. 115 y ss. Los delegados procuradores son encargados de la averiguación del estado del proceso del interno que lo solicite, realizar para el interno que lo solicite, trámites legales relacionados con su proceso; y registrar diariamente en el Libro de Autoayuda Legal las solicitudes y las acciones realizadas. 


\begin{tabular}{|l|l|}
\hline PERIODOS & CARACTERÍSTICAS \\
\hline Observación y clasificación & $\begin{array}{l}\text { Su cumplimiento se desarrolla en régimen cerrado con una duración } \\
\text { de dos meses desde el ingreso del condenado. Vencido este plazo, el } \\
\text { Consejo Penitenciario decide sobre el régimen que debe cumplir en } \\
\text { la segunda etapa. }\end{array}$ \\
\hline Readaptación social & $\begin{array}{l}\text { En esta etapa el condenado tiene la oportunidad de reintegrarse a la } \\
\text { sociedad, mediante la aplicación intensiva de técnicas individuales y } \\
\text { grupales de trabajo y estudio, dispuestas por el Consejo Penitenciario. }\end{array}$ \\
\hline Prueba & $\begin{array}{l}\text { Esta es una de las etapas más importantes, toda vez que tiene como } \\
\text { finalidad la preparación del condenado para su libertad, fomentan- } \\
\text { do la autodisciplina, tanto durante su permanencia en el estableci- } \\
\text { miento como en sus salidas. En esta etapa, el condenado puede optar } \\
\text { por diversos beneficios penitenciarios como: Salidas prolongadas y } \\
\text { extramuro } 24\end{array}$ \\
\hline Libertad condicional & $\begin{array}{l}\text { La libertad condicional es el último periodo del Sistema Progresivo. } \\
\text { Consiste en el cumplimiento del resto de la condena en libertad. }\end{array}$ \\
\hline
\end{tabular}

Fuente: Elaboración propia de acuerdo a la Ley 2298, arts. 164 - 174.

24. La figura del extramuro hace referencia a un beneficio penitenciario para los condenados clasificados en el periodo de prueba, este beneficio permite trabajar o estudiar fuera del recinto penitenciario, debiendo retornar al centro penitenciario al finalizar su jordana de estudio o de trabajo.

\section{LA GARANTÍA DE LOS DERECHOS FUNDAMENTALES EN LOS RECINTOS PENITENCIARIOS DEL ESTADO PLURINACIONAL DE BOLIVIA}

Los derechos fundamentales son aquellos [derechos] que se encuentran contemplados dentro de la Constitución Política, cuya garantía se encuentra bajo la responsabilidad del Estado. Estos derechos son los que permiten el desarrollo de la vida de las personas dentro de una determinada sociedad. En ese sentido el Profesor Bernardino Esparza (2013) precisamente explica que los derechos fundamentales son incorporados y reconocidos en los textos de cada una de las Constituciones, "para así conceder la positivización de los mismos derechos humanos en derechos fundamentales, que no es otro contexto, sino el de que los derechos humanos queden plenamente establecidos de una manera literal en la Ley Fundamental" (p. 73).

Por su parte, el Profesor Robert Alexy, citado por Bernal, 2015, indica que "un derecho fundamental es un todo, es decir, un conjunto de normas y posiciones de derecho fundamental que se adscriben interpretativamente a una disposición de derecho fundamental" (p. 1571). Una de las características esenciales, desde el punto de vista formal, que convierte a un derecho en fundamental tiene que ver con reunir ciertos requisitos, como el hecho de estar contemplado en un capítulo específico de la Constitución Política del Estado, además de provenir de pactos, convenciones o tratados de derechos humanos ${ }^{25}$. Por tal razón es que el Estado tiene la obligación de garantizar el respeto de tales derechos, salvo aquellos establecidos por la norma, en el presente caso se aplicaría la excepción sobre el derecho a la libertad.

Si bien los privados de libertad pierden este derecho, aún son sujetos activos de otros derechos fundamentales y el Estado mantiene esa obligación de garantizar el cumplimiento de aquellos derechos fundamentales, así lo ha expresado la CIDH (Corte Interamericana de Derechos Humanos ${ }^{26}$ sobre la responsabilidad

25. El Profesor Carlos Bernal Pulido explica sobre las propiedades fundamentales de los derechos que son considerados como fundamentales, cuya discusión es profunda y para el estudio de tales propiedades los clasifica en propiedades formales $y$ materiales. (Véase: Bernal, 2015).

26. Proveniente del Caso Chaparro Álvarez y Lapo Íñiguez Vs. Ecuador. Excepciones Preliminares, Fondo, Reparaciones y 
del Estado para la garantía de condiciones que respeten los derechos fundamentales y una vida digna de las personas privadas de libertad. Por otra parte, el Comité de Derechos Humanos, ha dejado en claro que el tratamiento a los reclusos con humanidad y respeto de su dignidad no debe depender de los recursos materiales que disponga el Estado, vale decir que esto no sirve como excusa por parte del Estado para no garantizar los derechos de las personas privadas de libertad.

En el caso de Bolivia, se debe tener en cuenta que para lograr el fin indicado tanto por la normativa internacional, la Constitución Política del Estado y las leyes infraconstitucionales en lo que refiere la finalidad de la pena basada en la protección a la sociedad contra el delito y lograr la enmienda, readaptación y reinserción social con responsabilidad del Estado, es necesario alcanzar una garantía real de los derechos fundamentales de las personas privadas de libertad por parte del Estado, toda vez que estas personas por su limitación al ejercicio del derecho a la libertad, se encuentran limitadas de poder atender por cuenta propia esas necesidades básicas. Por otra parte, también es necesario garantizar las suficientes condiciones que permitan allanar el camino hacia la resocialización. Para una mejor comprensión, se realiza un análisis detallado sobre las condiciones de infraestructura y derecho a la salud.

\subsection{SOBRE LAS CONDICIONES DE INFRAESTRUCTURA}

La infraestructura penitenciaria es muy importante porque se trata de los ambientes en donde los privados de libertad van a desarrollar su vida durante el tiempo que dure la sanción penal o la detención preventiva. Por lo tanto, el centro penitenciario no debe ser entendido como un lugar para administrar algún castigo, porque se admite que el castigo al recluso consiste en su propia privación de libertad. Para tal efecto, se debe tener en cuenta que un centro penitenciario debe reunir las condiciones adecuadas que permitan garantizar el respeto de los derechos fundamentales y el proceso de resocialización como lo establece la ley.

De acuerdo a lo indicado por las Reglas Mandela, específicamente por la Regla 13, la cual establece que los locales de alojamiento de

Costas. Sentencia de 21 de noviembre de 2007. los reclusos y, especialmente los dormitorios, deberán cumplir todas las normas de higiene, particularmente en lo que respecta a las condiciones climáticas y, en concreto, al volumen de aire, la superficie mínima, la iluminación, la calefacción y la ventilación. Por otra parte, la Organización de Naciones Unidas (ONU, 2017) explica que: "el vínculo entre la dignidad humana y un nivel de vida en prisión aceptable se observa muy claramente en especial en los casos en que la infraestructura general y las condiciones materiales de los establecimientos penitenciarios son muy deficientes" (p. 17).

A pesar que los arts. 13 y 84 de la Ley 2298 instituyen que el Estado garantizará que los establecimientos penitenciarios cuenten con la infraestructura mínima adecuada para la custodia y el tratamiento de los internos, el informe de la Defensoría del Pueblo de Bolivia revela que gran parte de los 20 centros penitenciarios de Bolivia se encuentran en estado de deterioro a razón de que estos centros fueron adecuados en edificaciones que no fueron construidas con ese fin, debido a esto, en la mayoría de los casos, no llegan a cumplir con las condiciones mínimas contempladas en la misma ley ${ }^{27}$. Esto lleva a la carencia de espacios esenciales para el adecuado funcionamiento, como, por ejemplo, la ausencia de espacios físicos para la recepción exclusiva de visitas ${ }^{28}$ y de espacios diferenciados para la revisión (requisa) de los visitantes, llegando al punto de atentar contra su pudor y dignidad ${ }^{29}$.

27. Al respecto, el art. 84 de la Ley 2298 establece que la estructura mínima consistirá en: Celdas adecuadamente equipadas y suficientes en función a su capacidad; servicios de asistencia penitenciaria; talleres y lugares de trabajo; biblioteca y aulas de enseñanza para los internos; servicio de alimentación; guardería para niños menores de seis años; instalaciones destinadas a discapacitados físicos; oficinas y servicios para el personal de seguridad, área administrativa; servicios sanitarios y de higiene; sistemas de recolección y recojo de basura; áreas de esparcimiento recreación y deportes; área de visitas; espacios para visitas conyugales y espacios para asistencia espiritual.

28. El informe indica que solo 4 centros penitenciarios a nivel nacional disponen de un espacio físico exclusivo para visitantes (San Antonio, San Pablo de Quillacollo y San Pedro de Sacaba los tres en el departamento de Cochabamba y Qalauma del departamento de La Paz). En cuanto a áreas destinadas a visitas conyugales, ninguno cuenta con ambientes exclusivamente construidos para aquello y las personas privadas de libertad adaptan sus celdas con ese fin.

29. Las áreas de requisa no aseguran la privacidad de las visitas. Por ejemplo en los Centros de Rehabilitación San Sebastián Mujeres, San Sebastián Varones, y San Pedro de Sacaba, no se dispone de ambientes o espacios diferenciados por sexo para la realización de este procedimiento. En Palmasola (Santa Cruz) y Morros Blancos (Tarija) además se atenta contra la dignidad, toda vez que se les exige descubrirse partes de su cuerpo. 
La delicada situación sobre la infraestructura en los centros penitenciarios de Bolivia, lleva a analizar otro tema muy sensible, el hacinamiento en los centros penitenciarios. De acuerdo a los datos emitidos por la Defensoría del Pueblo a través de una consulta realizada a la oficina de la Fiscalía General del Estado Plurinacional de Bolivia y la Dirección de Régimen Penitenciario, las cifras de hacinamiento son alarmantes y se expresan de la siguiente manera:

Tabla 4. Hacinamiento por centro penitenciario a septiembre 2017

\begin{tabular}{|c|c|c|c|c|}
\hline $\begin{array}{c}\text { CENTRO } \\
\text { PENITENCIARIO }\end{array}$ & CIUDAD & $\begin{array}{l}\text { POBLACIÓN } \\
\text { ACTUAL }\end{array}$ & CAPACIDAD & $\begin{array}{c}\text { PORCENTAJE } \\
\text { HACINAMIENTO } \\
\text { A } 2018\end{array}$ \\
\hline $\begin{array}{l}\text { Centro Penitenciario } \\
\text { Femenino de Miraflores }\end{array}$ & LA PAZ & 71 Pers. & 100 Pers. & $239 \%$ \\
\hline $\begin{array}{l}\text { Centro de Orientación } \\
\text { Femenina de Obrajes }\end{array}$ & LA PAZ & 298 Pers. & 245 Pers. & $239 \%$ \\
\hline $\begin{array}{l}\text { Centro de Rehabilitación } \\
\text { de Qalauma }\end{array}$ & LA PAZ & 236 Pers. & 150 Pers. & $239 \%$ \\
\hline $\begin{array}{l}\text { Centro Penitenciario de } \\
\text { San Pedro }\end{array}$ & LA PAZ & 2412 Pers. & 400 Pers. & $239 \%$ \\
\hline $\begin{array}{l}\text { Centro Penitenciario de } \\
\text { San Pedro de Chonchocoro }\end{array}$ & LA PAZ & 370 Pers. & 103 Pers. & $239 \%$ \\
\hline $\begin{array}{l}\text { Centro Penitenciario San } \\
\text { Pedro }\end{array}$ & ORURO & 719 Pers. & 250 Pers. & $252 \%$ \\
\hline $\begin{array}{l}\text { Centro de Readaptación } \\
\text { Productiva Santo Domingo } \\
\text { de Cantumarca }\end{array}$ & POTOSÍ & 484 Pers. & 150 Pers. & $151 \%$ \\
\hline El Abra & COCHABAMBA & 763 Pers. & 360 Pers. & $145 \%$ \\
\hline San Sebastián Varones & СОСНАВАМВА & 764 Pers. & 250 Pers. & $145 \%$ \\
\hline San Sebastián Mujeres & СОСНАВАМВА & 228 Pers. & 130 Pers. & $145 \%$ \\
\hline San Antonio & COСНАВАМВА & 493 Pers. & 240 Pers. & $145 \%$ \\
\hline San Pablo de Quillacollo & СОСНАВАМВА & 382 Pers. & 210 Pers. & $145 \%$ \\
\hline San Pedro de Sacaba & СОСНАВАМВА & 249 Pers. & 110 Pers. & $145 \%$ \\
\hline $\begin{array}{l}\text { Centro Penitenciario San } \\
\text { Roque }\end{array}$ & СОСНАВАМВА & 595 Pers. & 60 Pers. & $624 \%$ \\
\hline $\begin{array}{l}\text { Centro Penitenciario } \\
\text { Morros Blancos }\end{array}$ & TARIJA & 564 Pers. & 200 Pers. & $126 \%$ \\
\hline $\begin{array}{l}\text { Centro de Rehabilitación } \\
\text { Palmasola Varones }\end{array}$ & SANTA CRUZ & 5154 Pers. & 600 Pers. & $294 \%$ \\
\hline $\begin{array}{l}\text { Centro de Rehabilitación } \\
\text { Palmasola Mujeres }\end{array}$ & SANTA CRUZ & 374 Pers. & 200 Pers. & \\
\hline Mocoví Varones & BENI & 496 Pers. & 150 Pers. & $198 \%$ \\
\hline $\begin{array}{l}\text { Centro de Rehabilitación } \\
\text { de Trinidad Mujeres }\end{array}$ & BENI & 34 Pers. & 50 Pers. & $198 \%$ \\
\hline Villa Busch & PANDO & 437 Pers. & 128 Pers. & $227 \%$ \\
\hline
\end{tabular}

Fuente: Elaboración propia a partir de informe Defensoría del Pueblo (2018).

De acuerdo a la tabla que antecede, se puede evidenciar un dato preocupante sobre la ciudad de Chuquisaca que presenta un hacinamiento del $624 \%$ con 595 personas sobreviviendo en un espacio 
destinado para 60 personas, proyectándose de esta forma como la cárcel con mayor hacinamiento de acuerdo a su capacidad, seguida por el centro penitenciario Palmasola, en la ciudad de Santa Cruz. En el mismo sentido, se ha podido evidenciar el incremento de población penitenciaria en margen a la gestión 2017 - 2018 cuyas razones se estudiaran más adelante. Sin embargo, hay centros penitenciarios que a pesar de su limitada capacidad, presentan incremento entre un 10 y 20\% a la gestión 2018.

Tabla 5. Incremento de la población penitenciaria en Bolivia, 2017- 2018

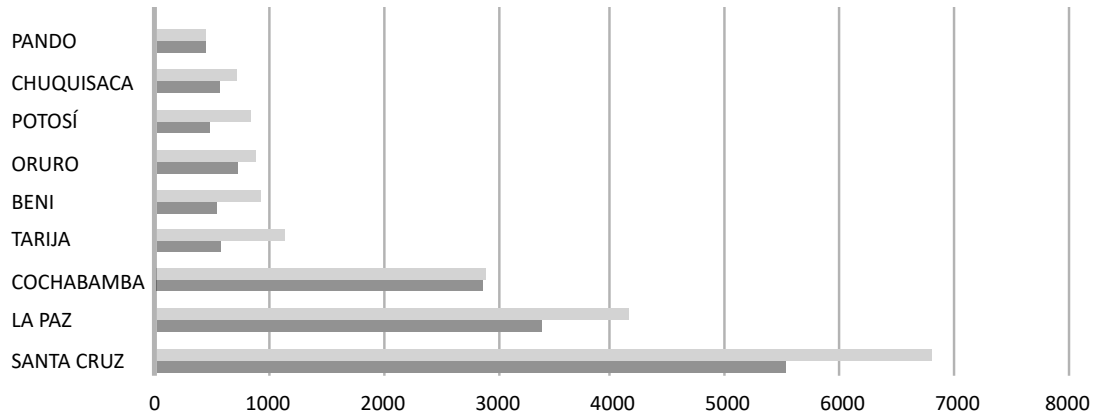

Fuente: Elaboración propia a partir de informe de Defensoría del Pueblo (2018).

Los datos expuestos sobre el hacinamiento obligan a realizar un análisis de tres problemas estructurales relacionados. En primer lugar, la sobrecarga procesal, en segundo, el abuso del poder punitivo $y$, finalmente, la falta de infraestructura que no permite a los privados de libertad acceder a un adecuado sistema de rehabilitación, como lo describe la ley. El hacinamiento y el funcionamiento de centros penitenciarios con infraestructuras improvisadas ocasionan que exista una ausencia de criterios de clasificación de la población penitenciaria como lo puntualiza tanto la Constitución Política del Estado, la Ley 2298 y las Reglas Mandela ${ }^{30}$. Los centros penitenciarios no cumplen con esta característica de clasificación por edad, gravedad del delito, situación jurídica, etc.

\subsection{SOBRE EL DERECHO A LA SALUD}

Al ser la salud un derecho fundamentalísimo, por su estrecha relación con el derecho a la vida al permitir el desarrollo y la existencia de la misma, no debe ser comprendido simplemente como la ausencia de enfermedad, toda vez que abarca una amplia gama de factores que

30. Con referencia a la Constitución Política del Estado, el art. 74 indica que es responsabilidad del Estado velar por su retención y custodia en un ambiente adecuado, de acuerdo a la clasificación, naturaleza y gravedad del delito, así como la edad y el sexo de las personas retenidas. Como se había mencionado con anterioridad esto también se encuentra legislado tanto en las Reglas Mínimas: 11, 12(2), 81 y arts. 75, 84, 85, 86 y 159 de la Ley 2298. permiten el desarrollo pleno de la calidad de vida, donde se incluye tanto el estado físico como el psicológico, este último punto es parte del Pacto Internacional de Derechos Económicos, Sociales y Culturales. La garantía de este derecho en los centros penitenciarios es de gran importancia, principalmente porque se trata de un grupo en desventaja en relación con la comunidad externa al centro penitenciario. Por ese motivo, la Regla 24 indica que es responsabilidad del Estado garantizar la prestación de servicios médicos a los reclusos y que estos servicios deben cumplir con los mismos estándares que están disponibles en la comunidad externa al centro penitenciario.

La Constitución Política del Estado Plurinacional de Bolivia, reconoce este derecho fundamental, resaltando que es obligación del Estado garantizar este derecho, para lo cual incluso amplia ciertas características como un Sistema Único de Salud. En el caso específico de las personas de libertad, la Ley 2298 menciona que cada centro penitenciario contará con un Servicio de Asistencia Médica, encargado de atención básica y de urgencia, en medicina general y odontología.

Como se había desarrollado en el anterior punto, la falta de una adecuada infraestructura es una de las razones que imposibilita garantizar un derecho tan fundamental como de la salud. A pesar de que el art. 90 de la Ley 2298 establece 
que el Servicio de Asistencia Médica deberá funcionar las veinticuatro horas para la atención de emergencias, el informe de la Defensoría del Pueblo revela que ningún centro penitenciario cuenta con una atención de este tipo para la población penitenciaria, constatándose que el $68 \%$ de los recintos la realiza en horario de oficina, el $11 \%$ en horario continuo y el $21 \%$ en otros horarios (Defensoría del Pueblo, 2018: 519). Por lo tanto, existe un incumplimiento no solo a lo establecido por la Ley 2298, sino también a lo dispuesto por la propia Constitución Política e instrumentos internacionales.

\section{FACTORES QUE INCIDEN EN EL INCREMENTO DE LA POBLACIÓN PENITENCIARIA}

Con la ayuda de la Tabla 6 , se puede observar un índice de incremento de la población penitenciaria en gran parte de los recintos penitenciarios de Bolivia, esto puede deberse a varios factores sociales pero, esencialmente, tiene estricta relación con la política criminal que el Estado desarrolla no solo para garantizar la seguridad de sus ciudadanos, sino para combatir la delincuencia en todas sus esferas. Lamentablemente, la política criminal con base en la que el Estado trabaja tiene que ver con el incremento en la severidad de las penas y la penalización de conductas. Esta política es conocida como populismo punitivo lo cual ha cambiado la imagen de los recintos penitenciarios, de centros de rehabilitación (como expresan las normas) a centros de represión (como refleja la realidad).

De acuerdo a lo señalado por Mellón, Rothstein y Álvarez (2016), para el populismo punitivo la cárcel es la única institución que puede incapacitar al delincuente. Razón por la cual es politizada y utilizada como arma electoral cuando se habla sobre la inseguridad, con el objetivo de obtener beneficios electorales. De acuerdo a Fuentes Osorio (2005, pp. 41-42), Pēres-Neto (2010, p. 283) y García-Borés (2015) citados por Antón, Rothstein y Álvarez (2016), los beneficios que obtiene la clase política de utilizar los criterios populistas punitivos son: (i) atender con inmediatez las demandas de la opinión pública; (ii) ofrecer la imagen que los políticos tienen capacidad de respuesta a los problemas; (iii) tranquilizante psicológico de que se están resolviendo los problemas y (iv) ocultar las causas estructurales por las que ocurren los delitos.

A través del populismo punitivo se trata de otorgar una respuesta sencilla a un problema estructural como la delincuencia (que puede ser provocada por la falta de políticas sociales de empleo) o la violencia intrafamiliar (que puede ser provocada por la falta de educación y concientización). Generalmente el legislador trata de evitar una discusión sobre el problema estructural porque puede significar mayor trabajo o mayor inversión financiera por lo que se limita a la exclusión del infractor a través de la creación de nuevos delitos o el incremento de las sanciones para mantenerlo más tiempo excluido de la sociedad (Arrieta, 2018, p. 40). Estas acciones siempre son bien recibidas por la sociedad que cree en el uso abusivo del derecho penal como una respuesta al abandono del Estado en la implementación de políticas públicas de prevención.

El abuso de la figura de la detención preventiva es otro de los factores que inciden en el incremento de la población penitenciaria; apoyados en los datos presentados por la Defensoría del Pueblo, se puede evidenciar que la mayoría de la población penitenciaria en Bolivia está compuesta por personas que se encuentran bajo la figura de detención preventiva.

Tabla 6. Situación jurídica en los recintos penitenciarios (a mayo 2018)

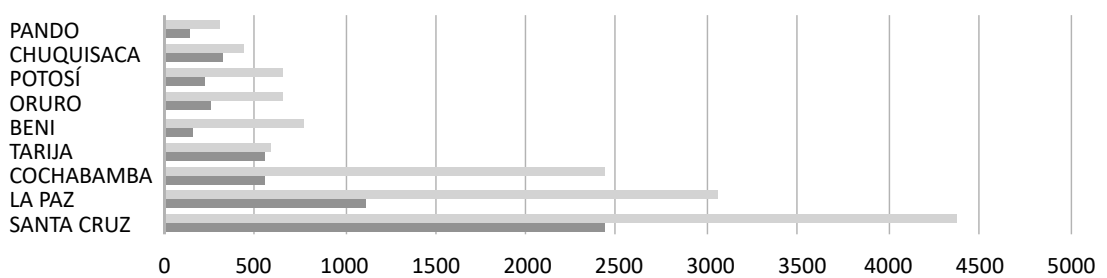

Fuente:Elaboración propia a partir de informe de Defensoría del Pueblo (2018). 
La regla de aplicación de la figura de detención preventiva se encuentra en el Código de Procedimiento Penal boliviano, cuyos principales requisitos para su otorgación son: la existencia del peligro de fuga (art. 234) y el peligro de obstaculización (art. 235). Dentro del artículo sobre la existencia del peligro de fuga se encuentran dos características esenciales que tienen que ver con el hecho de no contar con un domicilio o residencia habitual, negocios o trabajo lo que se traduce como facilidades para abandonar el país o permanecer oculto. Ante la ausencia de estos medios de arraigo natural, el Ministerio Público puede solicitar de manera fundamentada la aplicación de las medidas cautelares de carácter personal, sin embargo, es tarea del Juez realizar un análisis basado en los principios de legalidad, presunción de inocencia, necesidad y, sobre todo, proporcionalidad. Así lo ha expresado la CIDH, en el caso López Álvarez Vs. Honduras, que indica que la regla debe ser la libertad del procesado mientras se resuelve acerca de su responsabilidad penal.

En el párrafo 68 del fondo de reparaciones y costas del caso López Álvarez Vs. Honduras, la CIDH indica que:

La legitimidad de la prisión preventiva no proviene solamente de que la ley permite aplicarla en ciertas hipótesis generales. La adopción de esa medida cautelar requiere un juicio de proporcionalidad entre aquélla, los elementos de convicción para dictarla y los hechos que se investigan. Si no hay proporcionalidad, la medida será arbitraria (CIDH, p.40).

Bajo esa línea del principio de proporcionalidad, el Tribunal Constitucional de Bolivia a través de la Sentencia Constitucional Plurinacional 0806/2015-S3 y 0354/2017-S2 (Bolivia, 2015, 2017), ha indicado que, conforme lo determina el bloque de constitucionalidad, la regla es la libertad y, la excepción, la privación de libertad; debiendo esta ser invocada como última opción dentro de la figura de medidas cautelares. La imposición de las medidas cautelares de carácter personal ahondan el conflicto del imputado, encuadrándolo en una figura de desventaja, a diferencia de aquellos imputados que lograron una medida sustitutiva basado en un concepto netamente social.

\section{CONCLUSION}

Lamentablemente, Bolivia se desenvuelve en medio de una política criminal caracterizada por la represión y la prohibición, dejando de lado la política de prevención, educación y atención a las causales estructurales que conllevan a la comisión de un delito. El desenvolvimiento a través de esta política criminal ha hecho que la cárcel sea vista como un centro de castigo y, por ende, se ha deformado la finalidad de la pena descrita en la Ley 2298. Esto ha ocasionado que la realidad sea contraria a lo que establece la normativa al punto que, pareciera, la transición del sistema penal inquisitivo hacia el acusatorio ha sido de superficial y exclusivamente formal.

Este problema se ha profundizado a causa del populismo punitivo que, lejos de ser una alternativa de solución, se vuelve un agrietamiento más en el proceso de construcción de políticas públicas que permitan trabajar no solo en la reinserción social de los privados de libertad, sino también y de manera más enfocada en la prevención de la comisión de delitos. Las tablas presentadas reflejan de modo alarmante un alto porcentaje de hacinamiento en los recintos penitenciarios, incremento de la población penitenciaria y un alto índice de personas detenidas de forma preventiva, vale decir, sin sentencia. A eso se suma la precaria infraestructura carcelaria con la que se cuenta el país, espacios reducidos e improvisados para el funcionamiento de recintos penitenciarios.

A pesar de la reforma constitucional que otorga fuerza normativa a los derechos humanos y el mandato constitucional sobre la responsabilidad del Estado para la retención, custodia, respeto de sus derechos y la reinserción social de los privados de libertad, se ha podido evidenciar que existe una ausencia de políticas públicas dirigidas a este fin. De manera precisa, el Estado no ha podido garantizar el cumplimiento de las condiciones mínimas establecidas por la Constitución Política del Estado, Reglas Mandela o la propia Ley 2298, lo cual no permite garantizar los mecanismos que permitan la reinserción de los privados de libertad.

Es importante que el Estado pueda trabajar en la implementación de políticas públicas diseñadas para facilitar la reinserción social de los privados de libertad y mecanismos que permitan garantizar el respeto de los derechos fundamentales de los privados de libertad entre los cuales se encuentra las condiciones mínimas de habitabilidad. 


\section{BIGLIOGRAFÍA}

- Arrieta, Y. (2018). Populismo punitivo y Derecho Penal Simbólico. Inciso, 20 (1), 37 $-45$.

- Aráuz, M. (2002). El nuevo código procesal penal. Del proceso inquisitivo al proceso acusatorio. Revista de Derecho (1), 35 - 52. Recuperado de http://cort.as/-LOCj

- Barbosa da Silva, D. (2018, Ene - Abr). El sistema progresivo en España: Antecedentes históricos, rupturas y continuidades. Direito e Liberdade 20 (1), 11- 26 .

- Bastarreche, T. (2013, Abr - Jun). Jueces y Fiscales ante la instrucción. Cuestiones constitucionales. Revista de Estudios Políticos (nueva época) (160), 103 - 130. Recuperado de http://cort.as/-LQIL

- Bernal, C. (2015). Derechos Fundamentales. En J. L. F. Zamora y V. R. Blanco (Eds.), Enciclopedia de filosofía y teoría del derecho (pp. 1571 - 1594). Ciudad de México - México: UNAM.

- Bolivia. (2001). Ley de ejecución penal y supervisión 2298. Gaceta Oficial del Estado Plurinacional de Bolivia.

- Bolivia. (2006). Sentencia Constitucional 0045/2006. Tribunal Constitucional de Bolivia. Recuperado de: http://bit.ly/2OluFID

- Bolivia. (2009). Constitución Política del Estado Plurinacional de Bolivia. Gaceta Oficial del Estado Plurinacional de Bolivia. Recuperado de http://cort.as/-OObD

- Bolivia. (2015). Sentencia Constitucional Plurinacional 0806/2015-S3. Tribunal Constitucional Plurinacional de Bolivia. Recuperado de http://cort.as/-OOZB

- Bolivia. (2017). Sentencia Constitucional Plurinacional 0354/2017-S2. Tribunal Constitucional Plurinacional de Bolivia. Recuperado de http://cort.as/-OOZh

- Bolivia. (s.f.). Código de Procedimiento Penal Bolivia. Gaceta Oficial del Estado Plurinacional de Bolivia. Recuperado de http://cort.as/-OOag

- Comisión Interamericana de Derechos Humanos (CIDH). (2018). CIDH manifiesta su preocupación por personas muertas y heridas en cárcel de
Bolivia. Online. Recuperado de http://cort. as/-OOhw

- Defensoría del Pueblo, Estado Plurinacional de Bolivia, (2018). Volcar la mirada a las cárceles, situación de vulnerabilidad de las personas privadas de libertad en las cárceles de ciudades capitales de Bolivia. La Paz, Bolivia.

- Enríquez Rubio, H. (2013). La prisión. Reseña histórica y conceptual. Ciencia Jurídica 1 (2), 11-28. ISSN 2007-6142. Recuperado de: http:// bit.ly/2SbAyKc. DOI: https://doi.org/10.15174/ cj.v1i2.60.

- Esparza Martínez, B. (2013). Derechos Fundamentales. Ciudad de México: INACIPE.

- Ferrajoli, L. (2006). Garantismo Penal (1.a ed.). México, DF: UNAM.

- Ferrajoli, L., y dd. (2006). Sobre los derechos fundamentales y sus garantías (1.a ed.). México, DF: Comisión Nacional de los Derechos Humanos.

- Plataforma Ciudadana por el Acceso a la Justicia y los Derechos Humanos. (2019). Informe sobre el estado de la justicia en Bolivia 2018. La Paz: Fundación Construir.

- GARCIA, Sergio (1975). La Prisión. México: Fondo de Cultura Económica.

- Goffman, E. (1970). Internados (1.a ed.). Buenos Aires, Argentina: Amorrortu editores.

- Instituto Nacional de Estadística (INE). (2014). Bolivia: población estimada y proyectada por departamento según años calendario, 20002025. Online. Recuperado de http://cort. as/-MYob

- Lara, C.A. (2010). Funciones de control de defensa de la sociedad y de defensa del Estado; Análisis crítico. En UMSA, Vicepresidencia del Estado Plurinacional de Bolivia, Instituto Internacional para la Democracia y Asistencia Electoral (Eds.), Miradas nuevo texto constitucional (1.a ed., pp. 455 - 466). La Paz, Bolivia: IDEA Internacional.

- López Fernández, M. (2009, Jul - Dic). El concepto de anomia de Durkheim y las aportaciones teóricas posteriores. Iberóforum. 
Revista de Ciencias Sociales de la Universidad Iberoamericana, IV (8), 130-147.

- Martínez, B. (2013). Derechos Fundamentales. Ciudad de México - México: INACIPE.

- Mellón, J. A., Rothstein Pérez, P. A., y Álvarez, G. (2016). Populismo punitivo: Discursos que acompañan normas y políticas. En J. G. Bores y I. Rivera (Eds.), La cárcel dispar (cap. 5). Barcelona, España: Bellaterra, S.L.

- ONU. (1948). Declaración Universal de Derechos Humanos. Organización de Naciones Unidas. Recuperado de http://cort.as/-7DDH

- ONU. (2015). Reglas Mínimas de las Naciones Unidas para el Tratamiento de los Reclusos (Reglas Nelson Mandela). Oficina de las Naciones Unidas contra la Droga y el Delito. Recuperado de http://cort.as/-OObs
- Villamil, A. (2017). El proceso de resocialización en la Cárcel Modelo de Bogotá, una aproximación cualitativa [Licenciatura en Sociología]. Recuperado de http://cort.as/-Lmi5

- Yañez, A. (1999). Los sistemas procesales penales y la importancia del sistema acusatorio oral. Online. Recuperado de http://cort.as/-LQJ8 - -----. (1997). La filosofía del sistema penitenciario en el mundo contemporáneo. THĒMIS-Revista De Derecho. (35). 179 - 191. Descargado de: https://is.gd/reparado.

- Zaffaroni, R. (2015). La filosofía del sistema penitenciario en el mundo contemporáneo. En G. Bardazano, A. Corti, N. Duffau, y Nicolás Trajtemberg (Eds.), Discutir la cárcel, pensar la sociedad (1.a ed., pp. 15 - 36). Montevideo, Uruguay: Trilce. 